\title{
Trabalho e Escola: É Possível Conciliar? A Perspectiva de Jovens Aprendizes Baianos
}

\author{
Work and School: Is It Possible to Reconcile? \\ Perspectives from Apprentice Youngsters In Bahia \\ Trabajo y Escuela: ¿es Posible Conciliar? \\ La Perspectiva de Jóvenes Aprendices Baianos \\ (Del Estado de Bahia)
}

Elsa de Mattos \& Antônio Marcos Chaves

Universidade Federal da Bahia

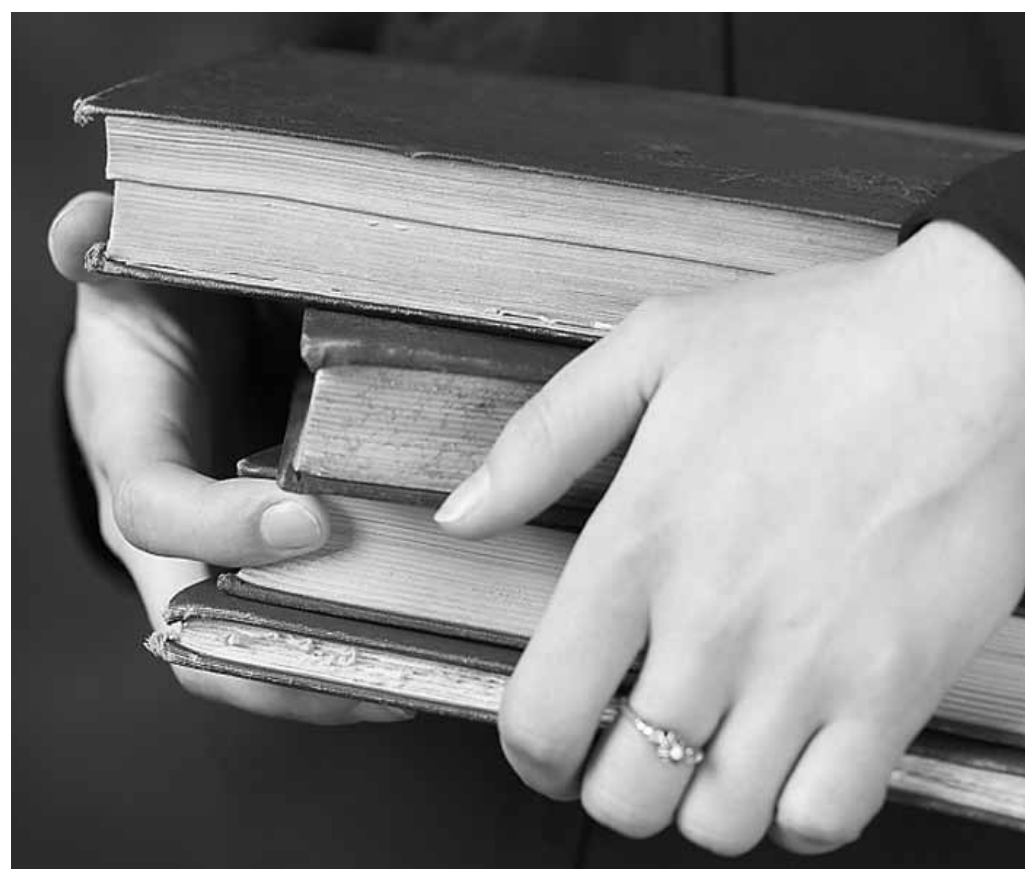


Resumo: A inserção no trabalho e a conclusão da escola são consideradas elementos fundamentais da inserção social no mundo adulto para uma parcela significativa da população jovem em nosso país, especialmente para aqueles que necessitam trabalhar a fim de ajudar no sustento da família. Este artigo relata parte de um estudo que investigou experiências de transição para o trabalho de adolescentes aprendizes baianos. O objetivo foi compreender os significados construídos pelos jovens acerca das relações entre trabalho e escola. Participaram da pesquisa 10 adolescentes, de ambos os sexos, com idades entre 17 e 19 anos, egressos de um programa de aprendizagem. A coleta de dados incluiu entrevistas, questionário sociodemográfico e observação participativa. A análise de conteúdo mostrou que escola e trabalho são percebidos como mundos distantes. Os resultados ressaltam o envolvimento ativo dos jovens para superar suas dificuldades e negociar oportunidades, mostrando que, para eles, trabalho e escola são projetos concomitantes.

Palavras-chave: Trabalho. Adolescentes. Escola. Educação. Desenvolvimento do adolescente.

\begin{abstract}
The transition to work and the conclusion of high school are considered fundamental markers of entrance into the social world of adult life for a significant number of young people in our country, especially for those who need to work to support themselves and their families. This article reports part of a study that investigated the experience of transition to work among adolescent apprentices in Bahia. The purpose was to understand the meanings constructed by the youngsters about the relationship between school and work. The study participants were ten adolescents, male and female, aged 17 to 19 years old, who concluded an apprenticeship program. Data collection included interviews, document review and participant observation in the context. Content analysis revealed that school and work are perceived as two worlds apart. Results highlight the active involvement of the youngsters to overcome their difficulties and negotiate opportunities, showing that, for them, work and school are concomitant projects.
\end{abstract}

Keywords: Labour. Adolescents. School. Education. Adolescent development.

Resumen: La inserción en el trabajo y la conclusión de la escuela son consideradas elementos fundamentales de la inserción social en el mundo adulto para una parcela significativa de la población joven en nuestro país, especialmente para aquellos que necesitan trabajar a fin de ayudar en el sustento de la familia. Este artículo relata parte de un estudio que investigó experiencias de transición para el trabajo de adolescentes aprendices baianos (del estado de Bahia). El objetivo fue comprender los significados construidos por los jóvenes acerca de las relaciones entre trabajo y escuela. Participaron en la pesquisa 10 adolescentes, de ambos los sexos, con edades entre 17 y 19 años, egresos de un programa de aprendizaje. La colecta de datos incluyó entrevistas, cuestionario socio-demográfico y observación participativa. El análisis de contenido mostró que escuela y trabajo son percibidos como mundos distantes. Los resultados resaltan el envolvimiento activo de los jóvenes para superar sus dificultades y negociar oportunidades, mostrando que, para ellos, trabajo y escuela son proyectos concomitantes.

Palabras clave: Trabajo. Adolescente. Escuela. Educación. Desarrollo del adolescente.

Um dos processos que marcam a transição para a vida adulta é a inserção na vida produtiva, a transição para o mundo do trabalho. Ao lado de aspectos como a constituição de relações afetivas estáveis e a finalização da escolarização básica, a inserção laboral é capaz de provocar alterações profundas nos comportamentos, nos papéis sociais e nas relações interpessoais dos jovens (Arnett, 2000; Sarriera, Silva, Kabbas, \& Lopes, 2001; Schulenburg, Bryant, \& O'Malley, 2004). A dimensão do trabalho, juntamente à escola e à família, vem sendo apontada como um dos condicionantes da inserção no mundo adulto para uma significativa parcela da população jovem em nosso país, especialmente para aqueles que necessitam trabalhar para ajudar no sustento da família (Camarano, 2004). No atual contexto brasileiro, tal processo ganha relevância especial, pois diversas pesquisas demográficas e atitudinais vêm apontando que o trabalho constitui importante referência para os jovens com mais de 15 anos, independentemente 
Alguns autores sugerem que 0 trabalho representa um fator de risco, sobretudo porque prejudica os estudos e contribui para o abandono escolar por parte dos jovens (Greenberger \& Steinberg, 1986; Teixeira, Fisher, Nagai, \& Turte, 2004). da origem socioeconômica, surgindo como o tema que, simultaneamente, mais os interessa e preocupa (IBASE/POLIS, 2006; Fundação Perseu Abramo, 2005; Guimarães, 2005). Nessa mesma linha, o trabalho é apontado como uma "categoria chave no imaginário juvenil" (Guimarães, 2005, p. 149).

Os pesquisadores, no entanto, questionam se o trabalho exercido na adolescência representa um risco ou uma oportunidade para o desenvolvimento. Alguns autores sugerem que o trabalho representa um fator de risco, sobretudo porque prejudica os estudos e contribui para o abandono escolar por parte dos jovens (Greenberger \& Steinberg, 1986; Teixeira, Fisher, Nagai, \& Turte, 2004). Outros estudos, no entanto, indicam que o trabalho não constitui intrinsecamente um risco, pois pode favorecer a permanência do adolescente na escola e aumentar seu interesse pelos estudos, dependendo das condições em que ocorre. Quando as condições são favoráveis, o trabalho pode fomentar o desenvolvimento do adolescente (Mattos \& Chaves, 2006; Mortimer, 2003; Newman, 1996).

Greenberger e Steinberg (1986) estão entre os autores que ressaltam as consequências negativas que a inserção laboral pode trazer para a vida dos adolescentes. Seus estudos, realizados com jovens americanos, sugerem que o trabalho intenso - i.e. aquele exercido por mais de 20 horas semanais - interfere na qualidade do aproveitamento escolar e pode favorecer o abandono da escola. No Brasil, estudos realizados por Teixeira et al. (2004) corroboram essa perspectiva, ressaltando os autores que o trabalho intenso combinado com o estudo pode ser fisicamente penoso na adolescência, envolvendo rotinas pesadas e provocando sobrecarga emocional.
Outras pesquisas, no entanto, demonstram que o trabalho na adolescência, especialmente nos anos finais da escolarização, pode trazer benefícios ao aproveitamento escolar. Nessa linha se encontram os estudos qualitativos realizados por Newman (1996) com jovens afro-descendentes moradores do subúrbio de Nova York. Seus resultados sugerem que a inserção laboral pode motivar os adolescentes a permanecerem na escola e a continuarem estudando. O caráter favorável da inserção laboral se evidencia melhor quando os jovens contam com apoio e incentivo de supervisores e colegas no ambiente de trabalho. Nessas condições, os adolescentes de classes menos favorecidas tendem a aumentar o interesse pelo estudo e melhoram o desempenho escolar.

Autores como Mortimer (2003) sugerem que as experiências de trabalho não são vividas de maneira homogênea por todos os adolescentes. Ao contrário, tais processos apresentam diferentes características e níveis de complexidade. Os pesquisadores argumentam que os efeitos do trabalho dependem da interação de múltiplos fatores, envolvendo tanto características individuais dos jovens quanto aspectos presentes no próprio contexto em que a atividade laboral ocorre. Mortimer ressalta ainda a necessidade de compreender as percepções dos adolescentes acerca de suas experiências de inserção laboral.

A revisão da literatura sobre a inserção laboral na adolescência sugere também que, ao lado da escola, da família e do grupo de pares, o trabalho pode constituir um agente complementar na socialização dos jovens, com papel fundamental no desenvolvimento de novas habilidades e 
na formação da identidade, contribuindo para construção de trajetórias positivas de desenvolvimento (Arnett, 2000; Mortimer, 2003; Schulenburg et al., 2004). A depender do contexto e das condições em que ocorre, o trabalho pode facilitar o desenvolvimento de responsabilidades e competências técnicas e profissionais e promover a aprendizagem de maneira ampla (Alves-Mazzotti, 1998; Mattos \& Chaves, 2006; Sarriera et al., 2001).

Diante dessas constatações, é necessário considerar que trabalho na adolescência é um fenômeno de natureza complexa e multifacetada, não se podendo estabelecer uma relação direta e linear do trabalho com situações que apresentam risco para o desenvolvimento. No Brasil, entretanto, as pesquisas sobre o trabalho realizado na adolescência tendem a desconsiderar a heterogeneidade dos aspectos relacionados com o trabalho adolescente. As experiências de inserção laboral permitidas pela legislação (Brasil, 2000), por exemplo, são pouco exploradas pela pesquisa acadêmica. Faz-se necessário, portanto, adotar uma perspectiva ampla, que possibilite entender melhor tanto os contextos e as condições em que o trabalho dos adolescente brasileiros pode ocorrer quanto as percepções e os significados que os jovens constroem acerca da relação entre trabalho e escola em contextos diferenciados. O presente estudo objetivou aprofundar essa compreensão, explorando as percepções e os significados que os adolescentes aprendizes constroem sobre suas experiências de transição para o mundo do trabalho.

\section{Trabalho e escola em um contexto de transformação}

Escola e trabalho constituem duas dimensões relevantes para a configuração das oportunidades dadas aos jovens no nosso país, especialmente no que se refere aos percursos ou às trajetórias possíveis de inserção social e profissional. No Brasil, as questões ligadas à educação e ao mercado trabalho apresentam nuances complexas, que fogem ao escopo do presente estudo. Entretanto, é importante refletir sobre alguns aspectos presentes em ambas as dimensões que podem facilitar ou dificultar a inserção social e profissional dos jovens brasileiros.

No atual contexto, o fenômeno da inserção laboral na adolescência acontece em um cenário marcado por transformações intensas tanto no âmbito econômico quanto no tecnológico e no institucional. De maneira geral, tais transformações são acompanhadas pela desregulamentação da ação do Estado e contribuem para aprofundar as desigualdades socio-econômicas, restringindo as oportunidades oferecidas às camadas mais desfavorecidas da população, especialmente aos jovens moradores das periferias (Braga \& Rodarte, 2006; Sposito, 2005). O processo também impõe novas demandas de escolarização e qualificação para a população em geral e, mais especificamente, para os jovens (Bastos, 2006; Madeira, 2006).

A educação, contudo, é cada vez mais considerada um fator estratégico na inserção socioprofissional (Abramovay, Lima, Pinheiro, Castro, \& Rodríguez, 2004; Sposito, 2005). Especialmente o nível médio de ensino parece funcionar como um passaporte para o mercado de trabalho formal, sobretudo para os jovens oriundos de famílias de baixa renda (Soares, Carvalho, \& Kipnis, 2003). No entanto, apesar de o Brasil ter avançado bastante nos últimos dez anos em relação ao acesso ao ensino médio, dados da UNESCO 
(2004) revelam que a maioria dos jovens brasileiros de 15 a 17 anos ainda cursa o ensino fundamental $(43,4 \%)$, enquanto uma parcela menor frequenta o ensino médio (35,7\%). A situação é ainda mais grave na Região Nordeste, onde 60\% dos adolescentes de 15 a 17 anos estão no ensino fundamental, enquanto somente $20 \%$ cursam no ensino médio. Dos que frequentam o ensino médio, mais da metade o faz no turno noturno, e grande parte na modalidade de supletivo. Além disso, um elevado contingente de adolescentes nessa faixa etária está fora da escola (são quase $20 \%$ na Região Nordeste). Em relação aos jovens de 18 a 24 anos, a situação é ainda mais crítica, pois uma parcela significativa $(37,1 \%)$ está fora da escola sem mesmo ter concluído o ensino fundamental. Em relação ao ensino superior, somente uma parcela mínima dos jovens tem acesso a esse nível educacional $(9,2 \%$ em todo o Brasil e $4,7 \%$ no Nordeste).

Pesquisadores salientam que tal situação decorre de uma combinação complexa de fatores intra e extraescolares, e envolvem tanto problemas internos ao sistema de ensino (i.e. falta de professores, professores mal remunerados, estrutura escolar debilitada, currículos defasados) quanto aspectos socioeconômicos e culturais (i.e. pobreza, nível de escolaridade dos pais). Dayrell (2003) ressalta que a baixa qualidade da escola contribui significativamente para a elevação das taxas de evasão e de reprovação entre os adolescentes, produzindo um verdadeiro estrangulamento do fluxo escolar nessa faixa etária. Conforme sinaliza o autor, a escola brasileira ainda se encontra fundamentada em modelos de transmissão de conhecimentos generalistas, priorizando a dimensão cognitiva da aprendizagem distanciada das experiências e das necessidades dos jovens. Por não acolher suas demandas, a escola acaba por excluí-los ou desmotivá-los.

No âmbito da educação, portanto, a baixa escolaridade se associa à baixa qualidade do ensino público e à ausência de oportunidades de qualificação profissional, colocando os jovens em situação particularmente desfavorável na conquista do seu passaporte para o mercado de trabalho. Por outro lado, as transformações que vêm ocorrendo no campo do trabalho, especialmente o surgimento de novas tecnologias e modelos organizacionais bem como o aparecimento e $\mathrm{O}$ desaparecimento de algumas ocupações, vêm produzindo uma redução dos empregos no setor da indústria, tradicionalmente ocupados pelos jovens (Pochmann, 2006), além do crescimento no desemprego estrutural.

De acordo com Pochmann, a combinação desses processos termina por transformar os jovens em um dos segmentos mais vulneráveis na busca pelo emprego, permanecendo eles mais tempo desempregados ou ocupando posições menos qualificadas no mercado de trabalho. A situação é ainda mais grave para aqueles que possuem atributos pessoais específicos, tais como os jovens negros moradores das periferias (Borges, 2006). No entanto, embora as oportunidades sejam escassas e o acesso ao trabalho esteja difícil, jovens de 15 a 24 anos estão cada vez mais à procura de empregos, compondo aproximadamente $26 \%$ da população economicamente ativa do País (Fundação Perseu Abramo, 2005).

No âmbito do macrocontexto, portanto, as dimensões da educação e do mercado de trabalho configuram espaços permeados por 
um conjunto de adversidades estruturais, que atuam como elementos constritores, criando sérios obstáculos à inserção laboral dos jovens, especialmente aqueles de baixa renda. Diante de tais circunstâncias, Sposito (2005) ressalta que a escola e o trabalho tendem a constituir projetos que se sobrepõem no universo de aspirações dos jovens e que podem sofrer ênfases diferenciadas de acordo com o momento e as condições vividas. Atualmente, no entanto, pouco se sabe sobre a forma como os jovens vivenciam tais processos.

A partir dessas considerações, constata-se que os aspectos estruturais e institucionais presentes na realidade brasileira têm influência marcante na inserção dos jovens no mundo do trabalho. No entanto, ainda são escassas as pesquisas que revelam os aspectos subjetivos associados a tais processos, abordando, por exemplo, a maneira como os jovens percebem e dão significado às suas experiências, negociam suas oportunidades no cotidiano, enfrentam o desemprego e a falta de oportunidades de trabalho. Torna-se necessário, portanto, desenvolver pesquisas voltadas para a compreensão da transição dos jovens para o mundo do trabalho a partir de uma perspectiva sistêmica que leve em conta, além dos fatores estruturais e contextuais, a maneira como os jovens interpretam suas experiências e as relações que estabelecem com a dimensão do trabalho e da escola. Estudos dessa natureza, focando especialmente as experiências dos adolescentes de baixa renda que frequentam programas de inserção laboral, tais como os programas de aprendizagem, têm o potencial de contribuir para um entendimento mais profundo dessas questões.
Nessa linha, o presente estudo buscou investigar as experiências de transição para o trabalho de jovens moradores da periferia de Salvador (BA), egressos de um programa de aprendizagem, com especial ênfase nas relações entre o trabalho e a escola. A Abordagem Ecológica do Desenvolvimento Humano, proposta por Bronfenbrenner (Bronfenbrenner, 1979/1996; Bronfenbrenner \& Evans, 2000; Bronfenbrenner \& Morris, 1998), foi considerada um modelo teóricometodológico que possibilita uma visão sistêmica e ecológica dos diversos contextos em que se inserem os adolescentes trabalhadores, enfocando especialmente as interações entre as dimensões da escola e do trabalho. Essa perspectiva é relevante, pois ressalta a forma como os jovens interpretam e atribuem sentidos a suas experiências e constroem suas trajetórias de desenvolvimento. A partir dessa perspectiva, portanto, o presente estudo considera que escola e trabalho são dimensões que se complementam no universo de vivência do adolescente trabalhador.

\section{Método}

\section{Participantes}

Os participantes deste estudo foram 10 jovens, 5 do sexo masculino e 5 do sexo feminino, com idades entre 17 e 19 anos, egressos de um programa de aprendizagem implementado por uma ONG localizada na cidade de Salvador. Os jovens foram selecionados entre aqueles que já haviam concluído há pelo menos seis meses o contrato de trabalho como aprendiz, com duração de 18 meses. As características dos participantes em relação à idade, ao nível de escolaridade e ao arranjo domiciliar encontram-se na Tabela 1, a seguir. 
Tabela 1. Características sociodemográficas dos jovens.

\begin{tabular}{|c|c|c|c|c|}
\hline Participantes & Sexo & Idade & Escolaridade & Arranjo domiciliar \\
\hline George & $M$ & 18 & $\begin{array}{l}\text { Ensino médio } \\
\text { completo }\end{array}$ & $\begin{array}{l}\text { Reside com } \\
\text { os pais e a irmã }\end{array}$ \\
\hline Talita & $\mathrm{F}$ & 18 & $\begin{array}{l}\text { Ensino médio } \\
\text { completo }\end{array}$ & $\begin{array}{l}\text { Reside com } \\
\text { os pais e irmãos }\end{array}$ \\
\hline Maurício & M & 19 & $\begin{array}{l}\text { Ensino médio } \\
\text { completo }\end{array}$ & Mora sozinho \\
\hline Jane & $\mathrm{F}$ & 18 & $\begin{array}{l}\text { Ensino médio } \\
\text { completo }\end{array}$ & $\begin{array}{l}\text { Reside com } \\
\text { os pais e a irmã }\end{array}$ \\
\hline Lúcio & M & 18 & $\begin{array}{l}\text { Ensino médio } \\
\text { completo }\end{array}$ & $\begin{array}{l}\text { Reside com } \\
\text { a avó }\end{array}$ \\
\hline Neuza & $\mathrm{F}$ & 18 & $\begin{array}{l}\text { Ensino superior } \\
\text { em curso }\end{array}$ & $\begin{array}{l}\text { Reside com } \\
\text { a mãe e os irmãos }\end{array}$ \\
\hline Nelson & M & 18 & $\begin{array}{l}\text { Ensino médio } \\
\text { incompleto }\end{array}$ & $\begin{array}{l}\text { Reside com } \\
\text { os pais e o irmão }\end{array}$ \\
\hline Diana & $\mathrm{F}$ & 18 & $\begin{array}{l}\text { Ensino médio } \\
\text { completo }\end{array}$ & $\begin{array}{l}\text { Reside com } \\
\text { a mãe e o irmão }\end{array}$ \\
\hline João Paulo & M & 19 & $\begin{array}{l}\text { Nível superior } \\
\text { em curso }\end{array}$ & $\begin{array}{l}\text { Reside com } \\
\text { a mãe e padrasto }\end{array}$ \\
\hline Maiara & $\mathrm{F}$ & 17 & $\begin{array}{l}\text { Nível médio } \\
\text { completo }\end{array}$ & $\begin{array}{l}\text { Reside com } \\
\text { o pai }\end{array}$ \\
\hline
\end{tabular}

* Os nomes dos participantes são fictícios

\section{Delineamento, instrumentos e procedimentos}

Este estudo utilizou o delineamento de estudos de casos coletivos (Stake, 1994). Em particular, foram investigados as mudanças e os desafios percebidos pelos jovens nesse processo. Entrevistas semiestruturadas foram realizadas com o objetivo de coletar dados sobre a inserção laboral, com especial ênfase nas relações entre a experiência de trabalho e a escola. Os dados biosociodemográfios dos participantes foram coletados através da aplicação de um breve questionário. Na entrevista, foram contempladas questões sobre a formação inicial desenvolvida no âmbito da ONG, as experiências de trabalho anterior, a experiência como aprendiz e as relações com a escola, entre outros aspectos relevantes para o entendimento da experiência de inserção no trabalho na condição de aprendiz. Após a aprovação do Comitê de Ética da universidade e a concordância por escrito da direção da ONG formadora, os jovens foram escolhidos para participar do estudo. 
A escolha foi realizada por conveniência e contou com o apoio dos educadores da ONG. Os jovens foram contatados por telefone e convidados a participar de um estudo sobre juventude e trabalho. Verificado o interesse em participar e a disponibilidade dos jovens, foram marcados os horários para a realização das entrevistas.

No momento do encontro, foram apresentados detalhadamente os objetivos da pesquisa, indicando que se tratava de um estudo sobre a relação entre trabalho e escola. Em seguida, aos adolescentes foi apresentado o Termo de Consentimento Livre e Esclarecido (TCLE), assinado pelos mesmos após concordância com os propósitos e os procedimentos adotados no estudo. No caso de uma das adolescentes, sendo ela menor de 18 anos, o genitor foi contatado na residência para maiores esclarecimentos acerca dos objetivos da pesquisa e assinatura do TCLE. Todas as entrevistas foram realizadas em um espaço reservado, localizado nas dependências da ONG formadora, com duração aproximada de uma hora e trinta minutos. As entrevistas foram gravadas em fitas cassete e posteriormente transcritas.

\section{Resultados}

Os dados foram submetidos à análise qualitativa, com a utilização do método proposto por Charmaz (2006) e também por Bardin (1977). A análise a seguir apresenta os aspectos destacados no relato dos jovens, considerando três temas centrais: (1) a escola, (2) o trabalho e (3) a relação entre trabalho e escola. As análises foram ilustradas com relatos dos participantes.

\section{(1) Escola}

Os jovens entrevistados apresentam níveis de escolaridade distintos; alguns ainda cursam o ensino médio e outros estão no primeiro ano do ensino superior. Todos os participantes foram unânimes em destacar a escola como um contexto importante de desenvolvimento, no qual as interações com os pares e a partilha de saberes se intensifica. A instituição escolar é valorizada pela sua importância na realização de objetivos futuros, tais como a inserção profissional. Nesse sentido, a escolaridade é vista como meta a ser perseguida, tanto por aqueles que ainda não concluíram o ensino médio quanto para os que pretendem ingressar ou já estão cursando a universidade:

\section{Estudar (tem que vir) sempre em primeiro lugar..., porque, depois, em algum lugar, vai precisar da escolaridade. E hoje as coisas estão difíceis. Se você não tiver um ensino bom, não tiver suas notas, ou então parar de estudar por causa do trabalho, não vai levar a nada. Então, tem que estudar. (Maiara, 17 anos)}

Os jovens que estão cursando o ensino médio ressaltaram os aspectos contraditórios de sua vivência na escola. Ao mesmo tempo em que revelam sua frustração com a escola e com o distanciamento que ela tem da realidade, ressaltam os esforços empreendidos no sentido de criar estratégias que os ajudem a permanecer estudando, tal como indica o depoimento a seguir:

Eu não consegui passar de ano. Me transferi pra noite, porque à noite é o tipo de curso que eu faço o $1^{\circ}$ e o $2^{\circ}$ ano. Eu estou tentando levar assim. Fica bem mais fácil pra mim. É como se fosse um supletivo. Agora eu tenho mais tempo, o tempo vago que eu tenho em casa é pra estar estudando.

(Nelson, 18 anos)

Esses depoimentos sugerem, conforme ressalta Dayrell (2007), que os jovens valorizam a escola como "uma promessa futura" (p. 1122), pela possibilidade que ela tem de garantir credenciais mínimas capazes de facilitar a inserção no mundo do trabalho. 
Os jovens também sugerem que a instituição escolar pode não estar cumprindo de maneira eficaz seus objetivos para com os alunos. Ela é apontada como um "mundo artificial", distante da vida prática e no qual os alunos não estão motivados para aprender:

Na escola a gente tem aquela coisa de faltar, de querer sempre estar conversando durante a aula... A escola forma a gente dizendo "o mundo tá aífora, o mundo tá aí fora", mas a gente nunca vê (esse mundo) na prática. (João Pedro, 19 anos)

Esses depoimentos revelem que a escola é percebida de forma ambígua pelos jovens, como um espaço necessário ao alcance de seus objetivos futuros, mas também distante da realidade cotidiana.

\section{(2) Trabalho}

Os jovens entrevistados percebem o trabalho como um ambiente próximo dos valores e objetivos pertencentes ao mundo adulto, tais como compromisso e concentração:

Quando você passa para o mercado de trabalho, você tem um compromisso ali. Você tem que bater ponto em tal horário e sair em tal horário. Os valores são diferentes. Os objetivos também são diferentes. Você passa a pensar mais como adulto. O adulto, lá no trabalho, ele já sabe se concentrar um pouquinho mais que o seu colega na sala de aula que no estudo não se concentra. (George, 19 anos)

O trabalho é percebido como ambiente propício ao desenvolvimento de novas competências e habilidades, da autonomia e da responsabilidade, capazes de favorecer a iniciativa. Dentre as competências adquiridas, os jovens apontam os conhecimentos técnicos e a melhor compreensão acerca de como se organiza o mundo profissional:

Eu não sabia como era o mercado de trabalho, não sabia como era o ambiente de trabalho. (Depois que comecei a trabalhar) eu pude saber realmente como as pessoas se comportam. Elas se comportam de forma bem séria. (Lúcio, 18 anos)

Os jovens também sugerem que sua autoconfiança aumentou, pois se sentem mais capazes de desempenhar tarefas, enfrentar desafios e atingir os objetivos propostos: "essa experiência de trabalho me deu a possibilidade de acreditar em mim mesma" (Diana, 18 anos). Os jovens também ressaltam o aumento da iniciativa, pois o trabalho fez com que eles passassem a selecionar e a direcionar ativamente suas ações, no sentido de correr atrás de seus objetivos: "No trabalho, tenho de correr atrás dos meus objetivos, superar os obstáculos. Se você quer alguma coisa, tem que correr atrás para conseguir, não (pode) desistir, tem que seguir em frente" (Maurício, 19 anos). Os jovens percebem que esses aspectos possuem um efeito positivo em suas vidas.

Alguns depoimentos, no entanto, também sugerem que pode ocorrer um excesso de responsabilidade associado ao trabalho. Essa situação ocorre quando o jovem fica sobrecarregado de tarefas, se sente estressado ou despreparado para as atividades que deve desempenhar:

É um trabalho que requer muitas atividades: tirar xerox de vários documentos, tem que fazer vários protocolos, solicitar (documentos) de outros setores.... Tudo lá tinha prazo. Eu precisava ter tudo em dia.... O tempo era curto porque eram quatro horas (de trabalho), as coisas começavam a se acumular para o outro dia. Às vezes, eu chegava em casa estressado e não conseguia estudar. Teve um momento que eu estava me sentindo muito sobrecarregado de tarefas. Era muito trabalho para uma pessoa só. (Nelson, 18 anos)

Em casos como esse, o jovem acaba assumindo responsabilidades que estão além da sua capacidade e do seu controle direto, e não consegue administrar adequadamente todas 
as demandas que surgem no cotidiano. Um das consequências, nesse caso, pode ser o aumento do estresse e, também, a queda do desempenho escolar.

\section{(3) Relação entre trabalho e escola}

Para os jovens entrevistados, a escola e o trabalho se apresentam como dois mundos distintos e distantes um do outro e que disputam seu tempo, atenção e dedicação. Nesse sentido, a relação do trabalho com a escola foi apontada pelos entrevistados como geradora de tensões e desafios a serem superados, pois o jovem se vê diante da necessidade de conciliar trabalho e estudo.

Para superar a falta de tempo para estudar e realizar as atividades escolares, os jovens sugerem que é necessário reorganizar a rotina diária para acomodar a atividade laboral, que ocupa boa parte do dia, em turno oposto à escola. O tempo gasto no deslocamento de ônibus entre o trabalho e a escola também foi apontado como uma dificuldade a mais a ser superada. Os jovens sentem que o tempo fica corrido, porque têm que ir da escola para o trabalho e precisam também se alimentar entre uma atividade e outra. Na maioria dos casos, o trabalho não fica próximo da escola que o jovem frequenta ou da sua residência, e o deslocamento de um lugar para outro é demorado. O depoimento a seguir evidencia melhor tais dificuldades:

Eu vinha correndo do colégio pra casa. Não dava tempo para tomar banho, nem almoçar. Só (dava para) vestir a camisa e ir pro ponto de ônibus. Já chegava (na empresa) faltando vinte minutos, quinze minutos, que era o tempo de comer alguma coisa pra poder iniciar o trabalho. Foi esse o desafio de adaptação no início, mas depois eu acostumei. (Maurício, 19 anos)

Diante das novas demandas, os jovens criam uma série de estratégias para lidar com as dificuldades cotidianas. Dentre as estratégias mencionadas, destacam-se: definição dos horários para estudar, maior atenção durante as aulas, entrega das atividades nos prazos, aumento da frequência do estudo (todos os dias), apoio dos professores para chegada ou saída das aulas em horários mais flexíveis, apoio de colegas da escola na obtenção de informações e materiais para estudo e apoio de supervisores e colegas de trabalho para permitirem que o jovem estude durante o horário de trabalho e para flexibilização dos horários de chegada e saída do trabalho. O depoimento a seguir revela algumas dessas estratégias:

O horário que eu chegava do trabalho, à noite, era o tempo que eu tinha pra estudar. O que tinha pra fazer, eu fazia (à noite). Na hora da aula, eu prestava bastante atenção. Aquilo era o que eu aprendia. Aí, eu anotava tudo. Às vezes, levava pro trabalho e estudava lá também, quando estava em época de prova. E dava pra aprender, pra estudar direitinho. Dava tempo, entre duas e três horas (da tarde) era o tempo que eu tinha. (Desse jeito), minhas notas melhoraram. (Jane, 18 anos).

Além dos esforços pessoais, a maioria dos jovens destacou que os professores são um elemento-chave para ajudá-los a enfrentar as novas demandas presentes no cotidiano. Muitos professores ficam sensibilizados com a condição dos alunos trabalhadores, compreendem suas necessidades e se dispõem a colaborar, explicando mais detalhadamente os assuntos e flexibilizando os horários de chegada e saída das aulas para aqueles que têm de se deslocar para lugares mais distantes. O depoimento a seguir mostra como o apoio dos professores pode ser essencial para que os jovens consigam superar o desafio de trabalhar e continuar estudando:

Eu posso dizer que todos os professores com quem eu conversei me deram o maior apoio. (Meu interesse em trabalhar) contou muito em termos de eu conseguir essa licença pra sair um pouco mais cedo (da escola), porque eles viram qual era a minha motivação, que era ganhar dinheiro... pra ajudar minha família e também para poder me manter. (Maurício, 19 anos) 
Os jovens ressaltaram também o apoio recebido de supervisores e colegas de trabalho. Um jovem, por exemplo, relatou que, quando necessitava ficar até mais tarde na escola, realizando algum trabalho ou reunião, seu supervisor o liberava.

Essas estratégias evidenciam, conforme sugere Bronfenbrenner (1996), que o jovem tem papel ativo nas escolhas e decisões tomadas no sentido de superar as dificuldades que se apresentam no seu cotidiano e na busca de integrar os diversos contextos nos quais circulam. Seus relatos evidenciam, também, que a dinâmica dos ambientes do trabalho e da escola depende de interações dos jovens com outros agentes significativos presentes nesses ambientes, tais como seus colegas de escola e professores.

Embora os jovens sejam hábeis em criar e implementar estratégias para conciliar trabalho e escola, nem sempre conseguem superar esse desafio de maneira satisfatória. Muitas vezes, as dificuldades não podem ser contornadas, e o jovem realmente acaba sendo prejudicado na escola. Conforme revela o depoimento a seguir, o estresse associado à responsabilidade em excesso e à falta de apoio no ambiente de trabalho pode levar à queda no aproveitamento escolar:

\begin{abstract}
Quando eu estava trabalhado e estudando, eu não tinha tempo para estudar. Até porque, às vezes, eu ficava muito preocupado quando alguma coisa saía do prazo. Eu recebia muito sermão lá quando alguma coisa saía do prazo. Aí, eu ficava muito preocupado e levava aquela preocupação... pra casa. Às vezes, eu chegava em casa estressado. (Nelson, 18 anos)
\end{abstract}

Nessas circunstâncias, o jovem se depara com tarefas cansativas e tem de assumir responsabilidades com as quais não tem condições de lidar sozinho. A situação se agrava ainda mais quando a própria escola, devido à rigidez de suas práticas, deixa de acolher suas necessidades:
(Eu tentei conciliar a escola com o trabalho.) Teve um tempo que eu falei com o professor e ele estava tolerando (que eu chegasse atrasado na aula). Eu falei sobre um curso (que estava fazendo), um tipo de estágio que eu fazia... Mas teve um certo momento que ele não deixava mais eu entrar na sala de aula. Eu cheguei a levar um atestado para a diretora da escola, mas ela simplesmente olhou e perguntou o que era aquilo, e disse que não poderia fazer nada, que eu ia perder aula todos os dias. Aí me prejudicou. A consequência foi que não consegui passar de ano. (Nelson, 18 anos)

O depoimento de Nelson mostra que as estratégias utilizadas pelos jovens para superar suas dificuldades, recorrendo aos professores e à direção escolar em busca de apoio, nem sempre produzem os resultados esperados. Em algumas situações, escola e trabalho podem estar tão distanciados a ponto de se tornarem antagônicos, fazendo emergir tensões e conflitos. Conforme ressaltam Dayrell (2003) e Sposito (2005), esse movimento termina por expor as contradições inerentes ao sistema educacional, cujas práticas se encontram distantes da experiência de seus alunos.

Nesse caso, os processos apresentam nuances e envolvem decisões que não dependem diretamente da atuação do jovem, que estão fora da sua esfera de influência e negociação. No entanto, têm forte impacto na sua trajetória de desenvolvimento. Nelson se vê sozinho diante da responsabilidade de enfrentar os riscos e as incertezas presentes no seu caminho. O resultado é desfavorável para ele, que acaba sendo prejudicado de maneira irreversível, repetindo o ano letivo. Nesse sentido, seu depoimento corrobora a visão sugerida por Dayrell de que o sistema escolar prioriza a dimensão cognitiva da aprendizagem e não acolhe as demandas dos jovens, culminando em um processo de exclusão de seus alunos. Quando a tarefa de conciliar escola e trabalho é deixada inteiramente sob a responsabilidade do próprio jovem, o processo pode culminar no fracasso escolar. Sobrecarregado e sem 
apoio, o jovem não consegue cumprir os compromissos escolares, e acaba por priorizar o trabalho.

Existem outras situações, no entanto, nas quais a impossibilidade de conciliar trabalho com estudo é superada mediante o afastamento da atividade laboral. O depoimento a seguir mostra que existem situações nas quais o jovem pode escolher dar prioridade aos estudos, por exemplo, quando estabelece como meta ingressar na universidade:

De manhã, eu ia pra escola, almoçava correndo, ia trabalhar e, depois do trabalho, eu voltava pro pré-vestibular. Chegou um momento em que eu não estava mais dando conta disso, e que eu tinha que escolher. Eu preferi... eu conversei com o gerente da empresa... que eu não poderia mais ficar, porque agora eu ia me preparar para o vestibular. (João Pedro, 19 anos)

O relato de João Pedro sugere que, diante da necessidade de conciliar trabalho e estudo, o jovem pode refletir sobre as oportunidades disponíveis e estabelecer como prioridade a continuidade dos estudos.

\section{Considerações finais}

Este estudo destinou-se a compreender melhor como os jovens trabalhadores, egressos de um programa de aprendizagem, percebem suas experiências e vivenciam as relações entre escola e trabalho. Para isso, explorou os significados que os jovens constroem acerca da escola, do trabalho e da relação entre ambos. Esta pesquisa compreende a inserção laboral na adolescência como transição ecológica (Bronfenbrenner, 1996; Bronfenbrenner \& Evans, 2000) capaz de promover uma reorganização qualitativa da experiência que envolve mudanças em diversos níveis da vida e que pode representar riscos ou oportunidades, a depender de como os jovens percebem e lidam com essas mudanças. Os adolescentes participantes do estudo foram tomados como agentes do seu próprio desenvolvimento, capazes de construir sentidos e significados acerca de suas experiências e, ainda, de criar estratégias de superação de seus desafios, negociando as oportunidades que se apresentam nos diferentes contextos em que transitam. Alem disso, buscou-se também elucidar as relações entre os jovens trabalhadores com os múltiplos contextos nos quais se inserem.

Uma análise do macrocontexto revelou as fragilidades presentes na dinâmica das oportunidades oferecidas aos jovens na nossa sociedade, que atuam no sentido de limitar as ações dos jovens. Escola e trabalho se apresentam como contextos fundamentais de inserção social dos jovens brasileiros oriundos de classes populares e que têm de trabalhar para sustentar a si mesmos e suas famílias. As experiências dos jovens entrevistados são marcadas pelo trânsito em ambos os contextos, e a inserção laboral na adolescência pode representar riscos e oportunidades conforme os elementos presentes no contexto em que ocorre e a percepção e a vivência que os adolescentes têm desse processo. Em relação à dimensão da educação, os jovens participantes deste estudo seguem valorizando a experiência escolar, embora de maneira ambígua. Seus depoimentos evidenciam o distanciamento existente entre os mundos da escola e do trabalho, apontando as tensões e as contradições vividas nas relações com esses ambientes.

Em relação à dimensão do trabalho na condição de aprendiz, a atividade é percebida 
como capaz de promover mudanças positivas, e envolve tanto o desenvolvimento de novas competências e habilidades, da autonomia e da responsabilidade assim como o aumento da iniciativa. Entretanto, trabalhar e estudar apresenta-se como um desafio cotidiano, e os jovens revelam a necessidade de desenvolver estratégias para conciliar as atividades nesses dois ambientes que disputam seu tempo, atenção e dedicação. Diversas estratégias foram destacadas pelos jovens para conciliar trabalho e estudo. Além de esforços pessoais, ressaltaram o apoio de professores, colegas de escola e também de supervisores e colegas de trabalho.

Contudo, em alguns casos, a rigidez do sistema educacional foi determinante para o fracasso escolar do jovem, revelando que, algumas vezes, a escola pode tornarse inflexível em relação às demandas dos alunos. Conforme sugere Dayrell (2007), embora esteja mais acessível às camadas populares, a escola ainda não se abriu verdadeiramente para receber esse público, não sendo capaz de estabelecer "um diálogo com os sujeitos e sua realidade" (p. 1117).

Nesse sentido, o jovem se defronta com um cenário marcadamente adverso para sua inserção social e profissional, cuja dinâmica de funcionamento não é capaz de atender as necessidades presentes nessa faixa etária, que envolvem, por exemplo, a criação de oportunidades para o desenvolvimento contínuo e a inserção profissional qualificada. Muitas vezes, ele é deixado sozinho diante da tarefa de superar os riscos e as incertezas que encontra no caminho. Sendo assim, percebe-se que, em um contexto no qual as possibilidades de inserção laboral para a juventude são limitadas e onde escola e trabalho se apresentam como mundos distantes, a inserção laboral é vivida como um processo complexo que depende das negociações que cada jovem pode fazer na sua interação com os elementos constritores presentes no seu contexto. Ressalta-se o papel preponderante dos professores, assim como o dos colegas de escola, na superação das dificuldades cotidianas vividas pelos jovens no sentido de integrar trabalho e estudo.

Nesse sentido, o presente estudo revela a necessidade de desenvolver programas sistêmicos e integrados que envolvam os jovens tanto em situações laborais quanto educacionais no âmbito da própria escola que frequentam. Trabalho e estudo são esferas concomitantes na vida dos jovens e não podem permanecer como projetos distintos, separados, distanciados, a ponto de os alunos perceberem o trabalho como real e escola como artificial. Situações de trabalho e de estudo devem ser conjugadas para que os jovens vivenciem a escola de forma mais próxima de suas realidades e necessidades. Os programas de aprendizagem, por exemplo, podem ser oferecidos no âmbito da própria escola em que os jovens estudam, através de convênios com instituições capacitadas para oferecê-los (Sistema S ou ONGs). Outra questão relevante é buscar uma integração maior, ou mesmo uma complementaridade, entre os conteúdos curriculares oferecidos pela escola e pelos programas de aprendizagem. Programas de abertura ao mundo do trabalho, tais como estágios regulamentares, podem também ser fomentados no âmbito da própria escola, sem que isso implique um distanciamento da vida acadêmica por parte dos alunos; pelo contrário, é uma maneira de aproximar a realidade do cotidiano dos alunos da vida escolar. Nesse sentido, o que se espera é que os resultados desta pesquisa possam 
apontar novos direcionamentos para as políticas públicas voltadas para a juventude, que possam gerar reflexões no âmbito dos governos e também dentro dos espaços de formação de jovens, seja no âmbito do ensino formal e informal, da escola e da universidade, ou das ONGs, seja na esfera das empresas, no sentido de promover intervenções voltadas para criar mais e melhores oportunidades para os jovens brasileiros. 
Elsa de Mattos*

Doutoranda em Psicologia pela Universidade Federal da Bahia, Bahia - BA - Brasil.

Antônio Marcos Chaves

Doutor em Psicologia Social. Docente na Universidade Federal da Bahia.

E-mail: amchaves@ufba.br

*Endereço para envio de correspondência:

Universidade Federal da Bahia, Rua da Graça. no 411/1201, Graça, Salvador, Bahia - Brasil CEP 40150-055.

E-mail: e.mattos2@gmail.com

Recebido 22/6/2009, 1a Reformulação 24/2/2010, Aprovado 10/3/2010. 


\section{Referências}

Abramovay, M., Lima, F. S., Pinheiro, L. C., Castro, M., Rodríguez, E. (2004). Políticas públicas DE/PARA/COM juventudes. Brasília, DF: UNESCO.

Arnett, J. J. (2000). Emerging adulthood: A theory of development from late teens through the twenties. American Psychologist, $55,469-480$.

Alves-Mazzotti, A. J. (1998). Trabalho infanto-juvenil: representações sociais de meninos trabalhadores, seus pais, professores e empregadores. In A. M. Paredes \& D. C. Oliveira (Orgs.), Estudos interdisciplinares de representação social (pp. 285-302). Goiânia: AB Editora.

Bastos, A. V. B. (2006). Trabalho e qualificação: questões conceituais e desafios postos pelo cenário de reestruturação produtiva. In J. E. Borges-Andrade, G. Abbad \& L. Mourão (Orgs.), Treinamento, desenvolvimento e educação em organizações e trabalho - fundamentos para a gestão de pessoas (pp. 23-40). São Paulo: Bookman.

Bardin, L. (1977). Análise de conteúdo. Lisboa: Edições 70.

Borges, A. (2006). Educação e mercado de trabalho: elementos para discutir o desemprego e a precarização dos trabalhadores escolarizados. Revista de Gestão: Ação Salvador, 9, 85-102.

Braga, T. S., \& Rodarte, M. M. S. (2006). A inserção ocupacional e o desemprego dos jovens: o caso das regiões metropolitanas de Salvador e Belo Horizonte. Pesquisa \& Debate, 17, 103-123.

Brasil. (2000). Lei $n^{\circ} 10.097$ de 19 de dezembro de 2000. Altera dispositivos da Consolidação das Leis do Trabalho - CLT, aprovada pelo Decreto-Lei n ${ }^{\circ} 5.452$, de $1^{\circ}$ de maio de 1943. Recuperado em 03 de maio de 2010, de http://www.planalto. gov.br/ccivil_03/Leis/L10097.htm

Bronfenbrenner, U. (1996). A ecologia do desenvolvimento humano: experimentos naturais e planejados. Porto Alegre: Artes Médicas. (Trabalho original publicado em 1979)

Bronfenbrenner, U., \& Evans, G. W. (2000). Developmental science in the 21st. century: Emerging questions, theoretical models, research designs and empirical findings. Social Development, 9, 115-125.

Bronfenbrenner, U., \& Morris, P. A. (1998). The ecology of developmental processes. In W. Damon \& R. M. Lerner (Eds.), Handbook of child psychology: Theoretical models of human development (Vol. 1, pp. 993-1027). New York: Wiley.

Camarano, A. A. (2004). Os caminhos dos jovens em direção à vida adulta. Desafios do Desenvolvimento. Revista do IPEA Instituto de Pesquisa Econômica Aplicada, 1, 59-62.

Charmaz, K. (2006). Constructing grounded theory. London: Sage.

Dayrell, J. (2003). Escola e culturas juvenis. In M. V. Freitas \& F. C. Papa (Orgs.), Políticas públicas - Juventude em pauta (pp. 173-189). São Paulo: Cortez.

Dayrell, J. (2007). A escola "faz" as juventudes? Reflexões em torno da socialização juvenil. Educação e Sociedade, 28(100 - Especial), 1105-1128.
Diálogo nacional para uma política de juventude. (2006). Rio de Janeiro: Ibase. Recuperado em 20 de outubro de 2007, de http://www.ibase.br/userimages/dialogo_juv_final21.pdf

Fundação Perseu Abramo. (2005). Perfil da juventude brasileira. Recuperado em 20 de abril de 2007, de http://www. projetojuventude.org.br/novo/assets/perfil_juventude_ brasileira.ppt\#1

Greenberger, E., \& Steinberg, L. D. (1986). When teenagers work: The psychological and social costs of teenage employment. New York: Basic Books.

Guimarães, N. A. (2005). Trabalho: uma categoria chave no imaginário juvenil? In H. W. Abramo \& P. P Branco (Orgs.), Retratos da juventude brasileira: análises de uma pesquisa nacional (pp. 149-174). São Paulo: Fundação Perseu Abramo.

Madeira, F. R. (2006). Educação e desigualdade no tempo de juventude. In A. A. Camarano (Org.), Transição para a vida adulta ou vida adulta em transição? (pp. 139-170). Rio de Janeiro: IPEA.

Mattos, E., \& Chaves, A. M. (2006). As representações do trabalho entre adolescentes aprendizes: um estudo piloto. Revista de Crescimento e Desenvolvimento Humano, 16, 66-75.

Mortimer, J. T. (2003). Working and growing up in America. Cambridge: Harvard University Press.

Newman, K. S. (1996). No shame in my game: The working poor in the inner city. New York: Vintage.

Pochmann, M. (2006). Mercado geral de trabalho: o que há de novo no Brasil? Parcerias Estratégicas, 22, 121-144.

Sarriera, J. C., Silva, M. A., Kabas, C. P., \& Lopes, V. B. (2001). Formação da identidade ocupacional em adolescentes. Estudos de Psicologia, 6, 27-32.

Schulemberg, J. E., Bryant, A. L., \& O'Malley, P. M. (2004). Taking hold of some kind of life: How developmental tasks relate to trajectories of well-being during the transition to adulthood. Development and Psychopathology, 16, 1119-1140.

Soares, S., Carvalho, L., \& Kipnis, B. (2003). Os jovens adultos de 18 a 25 anos: retrato de uma dívida da política educacional. Rio de Janeiro: IPEA. (Textos para Discussão, no 954)

Sposito, M. P. (2005). Algumas reflexões e muitas indagações sobre as relações entre juventude e escola no Brasil. In $\mathrm{H}$. Abramo \& P. P. Branco (Orgs.), Retratos da juventude brasileira: análises de uma pesquisa nacional (pp. 87-128). São Paulo: Fundação Perseu Abramo.

Stake, R. E. (1994). Case studies. In N. Denzin \& Y. Lincoln (Eds.), Handbook of qualitative research (pp. 236-247). London: Sage.

Teixeira, L. R., Fischer, F. M., Nagai, R., \& Turte, S. L. (2004). Teen at work: The burden of a double shift on daily activities. Chronobiology International, 21, 845-858.

UNESCO. (2004). Relatório de Desenvolvimento Juvenil - 2003. Brasília, DF: Autor. Recuperado em 20 de novembro de 2009, de http://unesdoc.unesco.org/images/0013/001339/133976por.pdf 